\title{
DESIGN OF A COMPACT CiRCUlaR MiCROSTRIP PATCH ANTENNA FOR WLAN APPLICATIONS
}

\author{
Chaitali Mukta1, Mahfujur Rahman ${ }^{2}$ and Abu Zafor Md. Touhidul Islam¹ \\ ${ }^{1}$ Department of Electrical and Electronic Engineering, \\ University of Rajshahi, Rajshahi 6205, Bangladesh \\ ${ }^{2}$ Department of Information and Communication Engineering, \\ University of Rajshahi, Rajshahi 6205, Bangladesh
}

\begin{abstract}
This paper presents the design of a compact circular microstrip patch antenna for WLAN applications which covers the band 5.15 to $5.825 \mathrm{GHz}$. The antenna is designed using 1.4mm thick FR-4 (lossy)substrate with relative permittivity 4.4 and a microstrip line feed is used. The radius of the circular patch is chosen as $7.62 \mathrm{~mm}$. To reduce the size and enhance the performance of the proposed antenna, a circular slot is loaded on circular patch and a square slot is etched on the ground plane of dimension 30mm $\times 30 \mathrm{~mm}$. Design of the antenna is carried out using CST Microsoft Studio Sonimulation Software. The proposed antenna resonates at $5.5 \mathrm{GHz}$ with a wider bandwidth of $702 \mathrm{MHz}$ and it provides low return loss of $-31.58 \mathrm{~dB}$, good gain of $3.23 \mathrm{~dB}$ and directivity of $4.28 \mathrm{dBi}$ and high efficiency of around $79 \%$ against the resonance frequency. The geometry of the proposed circular antenna with reduced size and its various performance parameters such as return loss, bandwidth, VSWR, gain, directivity, efficiency and radiation pattern plots are presented and discussed.
\end{abstract}

\section{KEYWORDS}

Circular patch antenna, WLAN, return loss, bandwidth, slot, FR-4 substrate, CST.

\section{INTRODUCTION}

Nowadays microstrip patch antenna can be used in variety of applications from military to commercial because of its distinguished features like small size, low weight, low profile, low fabrication cost, conformability to different shapes, consumes very less space, easy integration with printed circuit boards, easy fabrication and efficient directive radiation pattern $[1,2,3]$. The WLAN now plays a vital role for short distance wireless communication and users can access internet in their portable devices through this network.

Microstrip patch antennas have a plannar structure consisting of three layers, central insulating substrate layer and metallic radiating patch on its one side and a metallic ground on its other side. The energy radiations from the patch antenna take place due to fringing fields from the edges of the conducting patch [4]. There are many available shapes of radiating patch of the microstrip antennas such as rectangular, circular, square, triangular, elliptical, etc. Among them rectangular, circular and square shaped patch antennas are more commonly used because they are easy to design and analyze the performance [5]. As the circular patch antenna has one degree of freedom to control (radius), it is, therefore, simpler to design and its radiation can be easily controlled [6]. Also the size of the circular patch antenna is $16 \%$ less than that of the rectangular patch antenna at the same design frequency [7]. 
There are several methods to feed a microstrip patch antennas. The frequently used ones are microstrip line, coaxial probe and aperture coupling [2]. In the proposed circular patch antenna design, a microstrip line feed is used which consists of a conducting strip of a very small width compared to that of the patch. It is a contacting feed method where electromagnetic field coupling is used to transfer power between microstrip line and radiating patch.

Although microstrip patch antenna has been widely used in various wireless communication systems, there is a key requirement to have an efficient antenna that would be capable of transmitting signals with a low return loss, high data rate, high directivity and bandwidth. However, patch antennas suffer from low gain, small bandwidth, and comparatively large size at low frequencies [8]. In past years extensive research has been carried out to overcome these shortcomings of the patch antenna. A number of useful techniques have been proposed by the researcher to increase gain and enhance bandwidth $[9,10]$.

Some applications of the microstrip antenna in communication systems require smaller antenna size in order to meet the miniaturization requirements and hence size reduction of the patch antenna has attracted much attention. Circular microstrip patch antenna is very useful in this respect because of its small size and ease of fabrication. Different techniques have been suggested for achieving size reduction [11-16] like implementing slots in patch, implementing defected ground structure, use of high permittivity substrates, use of shorting pins, and introduction of parasitic patches.

The aim of this work is to design a compact circular microstrip patch antenna that shows good performance with respect to state-of-the-art designs. The proposed antenna use the method of implementing slots on the patch and ground layers for achieving size reduction and microstrip line feed to operate in the WLAN applications which cover 5.15 to $5.825 \mathrm{GHz}$ band. The antenna is design and simulated in CST Studio Suite 2015 software.

The rest of the paper is organized into several sections. Section II presents a review of the related literature, while Section III formally describes the antenna design methodology. Simulation results are presented and analyzed in Section IV. Finally, Section IV ends the paper with some concluding remarks.

\section{Literature REVIEW}

Authors in [20] proposed a circular microstrip antenna with a circular slot is etched on the circular patch to provide wideband operation. Design parameters were FR-4 epoxy substrate $\left(\varepsilon_{\mathrm{r}}=\right.$ 4.4) with ground plane dimension $25 \mathrm{~mm} \times 25 \mathrm{~mm}$, radius of the circular patch $6.96 \mathrm{~mm}$ and substrate thickness $1 \mathrm{~mm}$. They design and simulate the antenna to operate in $5.8 \mathrm{GHz}$ in Finite Element Method (FEM) based High Frequency Structural Simulation (HFSS ${ }^{\mathrm{TM}}$ ) tool. They found a low return loss of $-29 \mathrm{~dB}$ with a wider bandwidth of $660 \mathrm{MHz}$.

A coplanar waveguide (CPW) fed circular patch monopole antenna for WLAN/WiMAX applications is presented in [21]. To reduce the size of conventional antenna and widen its bandwidth the patch is loaded with slots. Their simulated result has a $-10 \mathrm{~dB}$ impedance bandwidth of $2.46 \mathrm{GHz}$ in the band of $4.97-7.43 \mathrm{GHz}$.

An overview of circular microstrip antenna design is presented in [22] where it was concluded that circular microstrip antenna can be designed for different frequency band and different feeding methods like coaxial, strip line, aperture coupling or proximity coupling are available for different substrate materials to excite the antenna. 
In [23], a comprehensive review of the recent research work done by various authors on the design and optimization of the slotted circular microstrip patch antenna operating in $\mathrm{C}$ band is presented. The slotted antennas are used in $\mathrm{C}$ Band applications like satellite communication, WLAN, WiMAX, Wi-Fi etc. They concluded that the introduction of different slots on the antenna have resulted in improvement of various performance parameters of the antenna like gain, bandwidth, return loss etc.

A composite dual band circular microstrip patch with space opening for WLAN applications is presented in [24]. The antenna configuration is simulated and analyzed with HFSS. A narrow band high gain circular patch antenna has been designed for GSM1800 band and presented in [25]. They found the return loss is $-21 \mathrm{~dB}$ at $1.8 \mathrm{GHz}$ for $\mathrm{VSWR} \leq 2$. The gain of antenna was increased by inverted suspended circular patch with same dimension of radiating patch from 7.5 $\mathrm{dB}$ to $8.5 \mathrm{~dB}$ and also it was increased from $8.2 \mathrm{~dB}$ to $8.5 \mathrm{~dB}$ by increasing the gap between top and bottom patch from $1 \mathrm{~mm}$ to $4 \mathrm{~mm}$.

Authors in [26] presented the design of a circular patch antenna operating at $5 \mathrm{GHz}$ for $\mathrm{C}$ band applications. The antenna is designed using FEM based EM simulator software - Ansoft's HFSS v13. In [27], author reported that the bandwidth of microstrip patch antenna increases with the help of slots. By using different shape of slot the gain of microstrip patch antenna can also be improved and antenna straucture can be made more compact.

\section{Antenna Design}

The proposed circular microstrip patch antenna is designed using CST Studio Suite 2015 software. Once the design is complete, the antenna can be simulated in the software to estimate its real world performance. For antenna design, it is assumed that the dielectric constant of the substrate $\left(\varepsilon_{r}\right)$, the resonant frequency $\left(f_{r}\right.$ in $\mathrm{GHz}$ ), and the height of the substrate $\mathrm{h}$ (in $\mathrm{mm}$ ) are known. Then a set of simplified equations of cavity model is used for calculating design parameters of circular microstrip patch antenna as follows.

Radius of the circular patch is given by [28]:

$$
a=\frac{F}{\left[1+\frac{2 h}{\pi F \varepsilon_{r}}\left(\ln \left\{\frac{\pi F}{2 h}\right\}+1.7726\right)\right]^{0.5}}
$$

where,

$$
F=\frac{8.791 \times 10^{9}}{f_{r} \sqrt{\varepsilon_{r}}}
$$

$\varepsilon_{r}=$ Dielectric constant of substrate

Length and width of the substrate can be calculated by

Substrate length, $L_{\text {sub }}=2 \times 2 a$

Substrate width, $W_{\text {sub }}=2 \times 2 a$ 
International Journal on AdHoc Networking Systems (IJANS) Vol. 11, No. 3, July 2021

For WLAN band (5.15-5.825) GHz, antenna design parameters are calculated as follows. Here FR4 (lossy) substrate is used with dielectric constant 4.4 and the of the substrate height is chosen as $1.4 \mathrm{~mm}$. Then

(1) Resonance frequency $f_{r}=\frac{5.15+5.825}{2}=5.4875 \mathrm{GHz} \approx 5.5 \mathrm{GHz}$

(2) $F=\frac{8.791 \times 10^{9}}{f_{r} \sqrt{ } \varepsilon_{r}}=7.619 \mathrm{~mm}$

Radius of the circular patch $=\frac{F}{\left[1+\frac{2 h}{\pi F \varepsilon_{r}}\left(\ln \left\{\frac{\pi F}{2 h}\right\}+1.7726\right)\right]^{0.5}}=6.4 \mathrm{~mm}$

(3) Substrate length, $L_{\text {sub }}=2 \times 2 a=25.6 \mathrm{~mm}$

Substrate width, $W_{\text {sub }}=2 \times 2 a=25.6 \mathrm{~mm}$

Once we get calculated values of the antenna parameters, trial and error method is used to improve the performance of the proposed antenna along with its size reduction. The geometry of the proposed circular patch antenna is shown in Fig. 1. The radius of the circular patch is taken as $7.62 \mathrm{~mm}$ and the antenna is printed on a FR4 (lossy) substrate having relative permittivity of 4.4 and substrate thickness of $1.4 \mathrm{~mm}$. The dimension of ground plane, which is printed in the bottom side of the substrate, is chosen to be $30 \mathrm{~mm} \times 30 \mathrm{~mm}$. A circular slot is cut from the circular patch and a square slot is cut from the ground plane to enhance the performance of the proposed antenna. The radius of the circular slot is used as $4.5 \mathrm{~mm}$ and the dimension of the square slot is $19 \mathrm{~mm} \times 19 \mathrm{~mm}$. Amicrostrip feed line with dimensions $6 \mathrm{~mm} \times 2 \mathrm{~mm}$ is used with the circular patch to achieve the impedance matching $50 \Omega$ between the patch antenna and the transmission line. The detailed dimensions of the proposed antenna are shown in table 1.

Table 1. Design Parameters and corresponding values

\begin{tabular}{|c|c|c|c|c|}
\hline Parameter & Length(mm) & Width(mm) & Height(mm) & Material \\
\hline Ground & 30 & 30 & 0.035 & Copper (annealed) \\
\hline Substrate & 30 & 30 & 1.4 & FR-4 (lossy) \\
\hline Microstrip line feed & 6 & 2 & 0.035 & Copper (annealed) \\
\hline Patch & \multicolumn{3}{|c|}{ Radius $=7.62 \mathrm{~mm}$} & Copper (annealed) \\
\hline
\end{tabular}

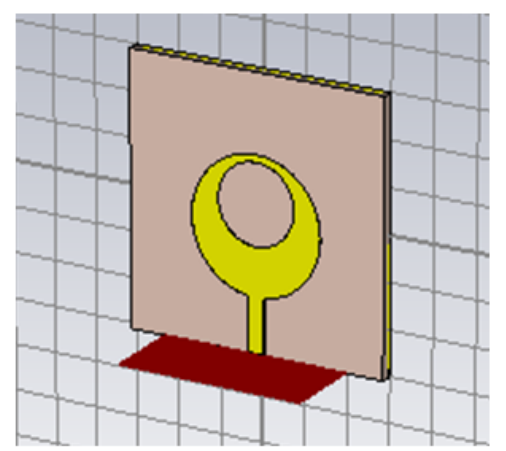

Perspective view

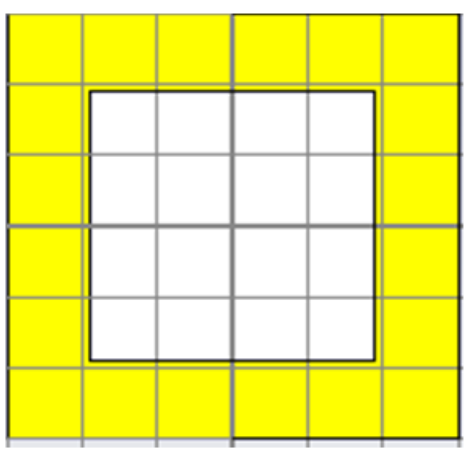

Back view

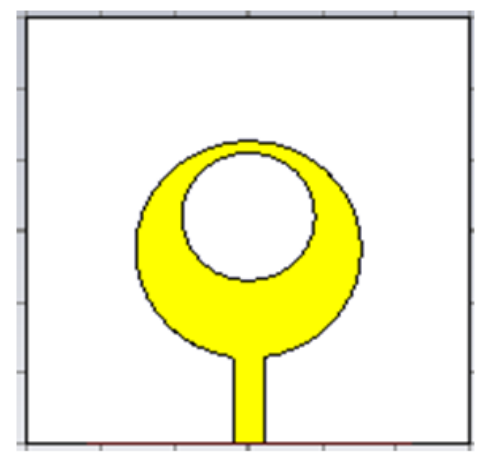

Front view

Figure 1. Geometry of proposed circular patch antenna 


\section{Simulation Results and Discussion}

The proposed circular microstrip patch antenna is designed and simulated using CST simulation software. An optimization between size reduction and performance enhancement is maintained in this work until satisfactory results were obtained. The performance of the proposed antenna is investigated in terms of the following parameters: return loss, bandwidth, VSWR, gain, directivity, total efficiency, and radiation pattern.

\subsection{Return Loss}

Return loss or S parameter indicates how much electromagnetic power from the microstrip patch antenna is returning back (reflected power) and therefore it is known as reflection coefficient. It determines the quality with respect to impedance match between the sending end (source) and the receiving end (measured load). To obtain a successful radiation mode, return loss must be below $10 \mathrm{~dB}$. Figure 2 shows the $\mathrm{S}$ parameter versus frequency plot of the proposed antenna. It is seen that the resonance frequency of the proposed antenna is $5.5 \mathrm{GHz}$. The curve shows return loss of the antenna is $-31.58 \mathrm{~dB}$ at $5.5 \mathrm{GHz}$ which indicates the impedance match is better and the energy loss is lesser.

The bandwidth of the designed antenna can be determined from Fig. 2 as the frequency range bounded by a return loss of less than $-10 \mathrm{~dB}$. The estimated $-10 \mathrm{~dB}$ impedance bandwidth of the antenna is $0.7019 \mathrm{GHz} \approx 702 \mathrm{MHz}$ (from $5.129 \mathrm{GHz}$ to $5.8309 \mathrm{GHz}$ ) which implies that the proposed antenna satisfying the WLAN bands of (5.15-5.825) GHz.

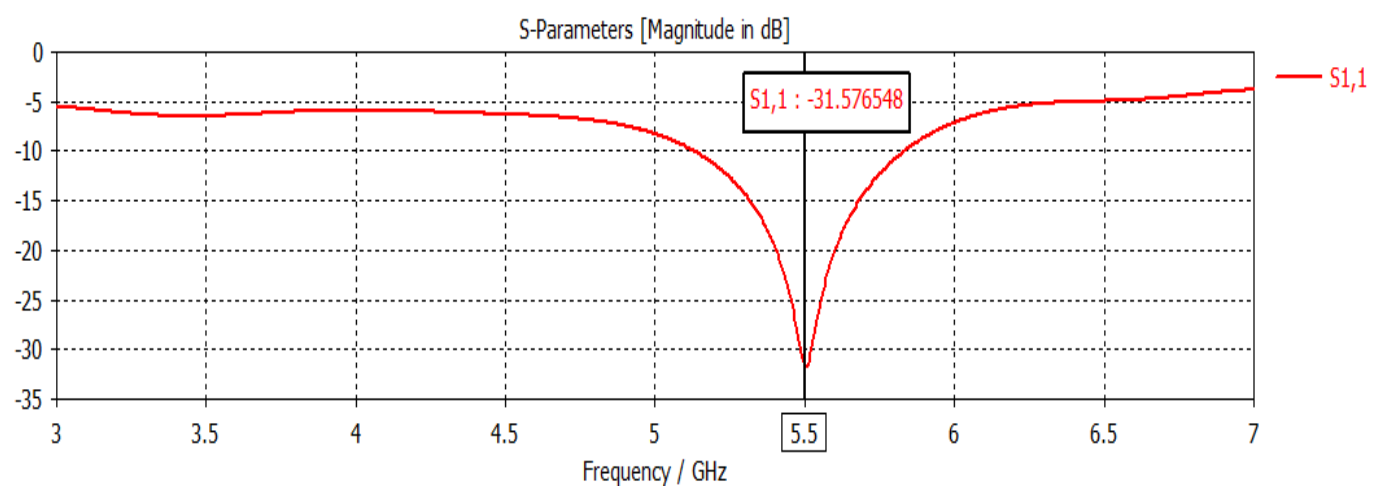

Figure 2. S-Parameter Vs. frequency curve of the proposed antenna

\subsection{Voltage Standing Wave Ratio (VSWR)}

The impedance mismatch between antenna and transmission line is measured by VSWR. The VSWR value of less than 2 is acceptable for a good design antenna. Fig. 3 shows VSWR Vs. frequency plot of the proposed antenna and it is seen that at the resonance frequency of $5.5 \mathrm{GHz}$ the value of VSWR is 1.054 which much less than 2. The lower VSWR indicating better impedance match of the proposed antenna to the transmission line, and the higher the power supplied to the antenna. 


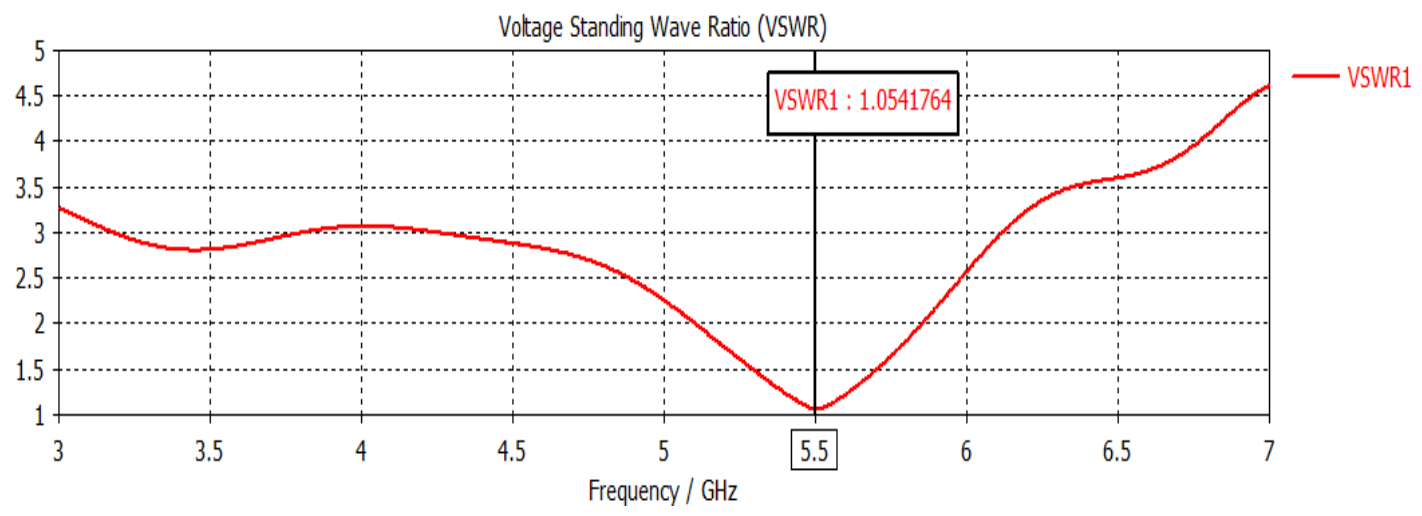

Figure 3. VSWR Vs. frequency curve of the proposed antenna

\subsection{Gain}

The parameter gain describes how efficient an antenna can send out or receive power in a particular direction. In other words, it indicates how much power is transmitted in a given direction to the radiation intensity that would be produced by an isotropic antenna. Figure 4 shows the 3D plot of far-field gain of the proposed antenna and the estimated peak value of gain is $3.229 \mathrm{~dB}$ at the resonance frequency of $5.5 \mathrm{GHz}$.

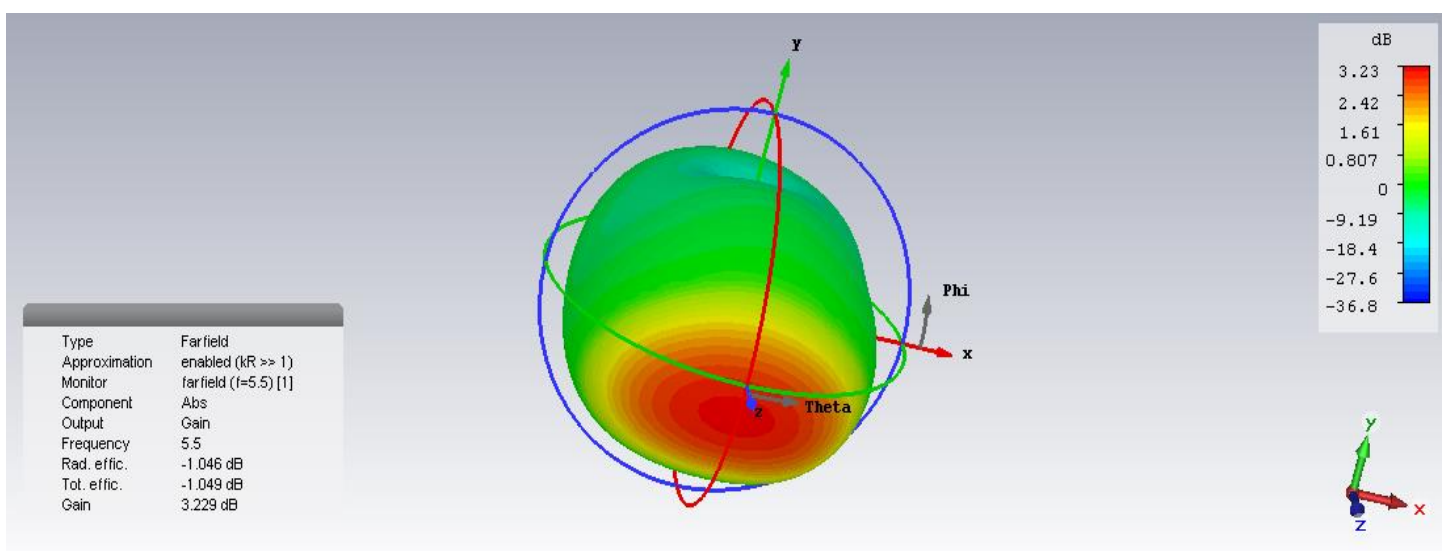

Figure 4. 3D plot of far-field gain at $5.5 \mathrm{GHz}$

\subsection{Directivity}

The directivity measures how much intensely the antenna radiates power in its preferred direction and is defined by the ratio of the maximum power density to its average value over a sphere as observed in the far field. The 3D plot of far-field directivity of the proposed antenna at the resonance frequency of $5.5 \mathrm{GHz}$ is shown in Fig.5. It is noticed that the peak value of directivity of the designed antenna is $4.275 \mathrm{dBi}$. 


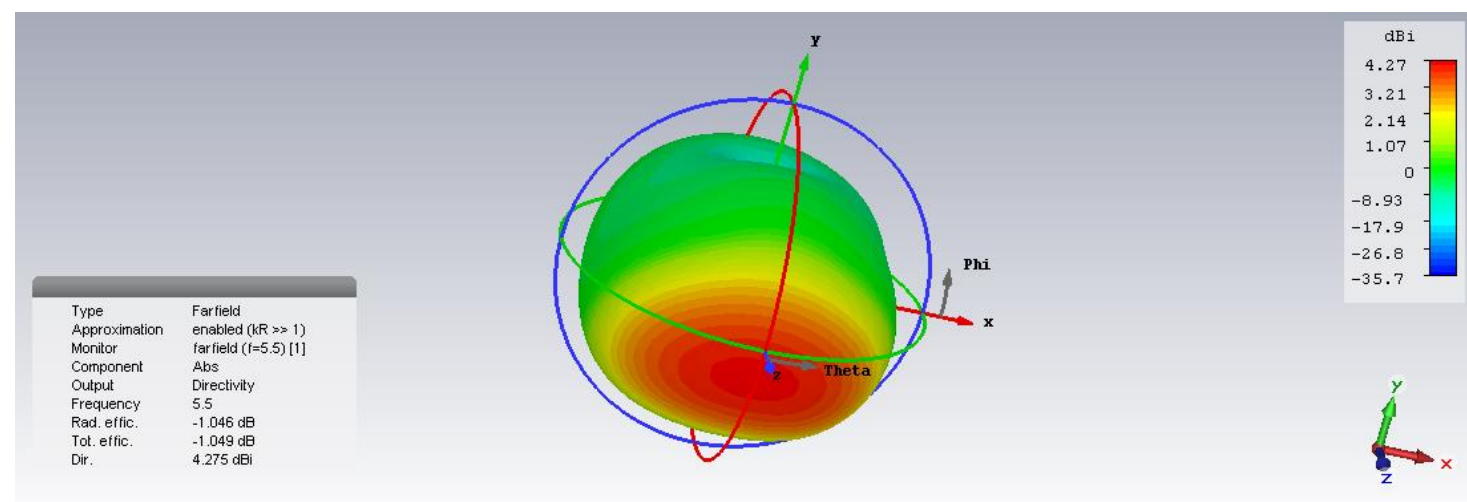

Figure 5. 3D plot of far-field directivity at $5.5 \mathrm{GHz}$

\subsection{Total Efficiency}

Antenna efficiency is defined as the ratio of the radiated power to the incident power at the antenna in percentage. Figure 6 shows the total efficiency Vs. frequency curve of the proposed antenna. It is observed that antenna efficiency is above $67 \%$ over the entire operating band $(5.13$ $\mathrm{GHz}-5.83 \mathrm{GHz}$ ) with a maximum value of around $79 \%$ is achieved at the resonance frequency of $5.5 \mathrm{GHz}$.

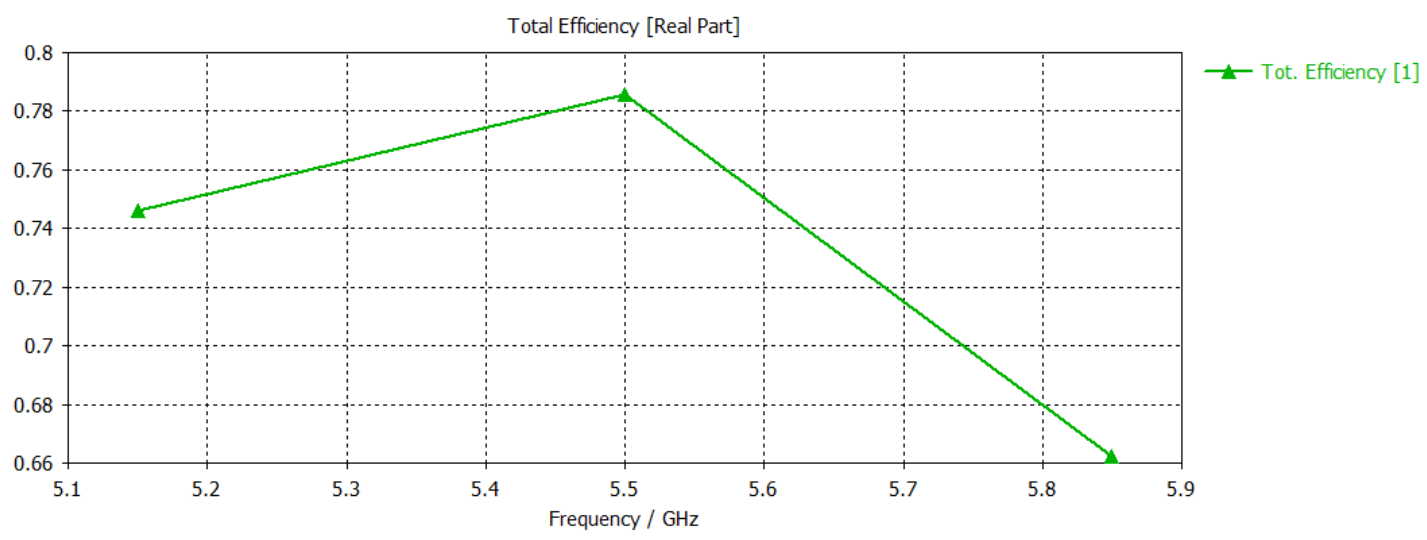

Figure 6. Total efficiency Vs. frequency curve of the proposed antenna

\subsection{Radiation Pattern}

The radiation pattern is the distribution of the radiated power from the antenna (in the case of transmitting antenna), or received by the antenna (in the case of receiving antenna) as a function of the direction angles from the antenna. In most cases, it is calculated in the far-field region and explains both the E-field and $\mathrm{H}$-field patterns.

\subsubsection{E-field pattern}

The polar plot of Far-field E-field pattern of the proposed antenna at $5.5 \mathrm{GHz}$ is shown in Fig.7. It is seen that the main lobe magnitude is $18 \mathrm{dBV} / \mathrm{m}$ and direction of main lobe is 10 degree. Fig. 8 shows the 3D plot of the Far-field E-field pattern of the designed antenna which shows the maximum radiation intensity $E_{\max }$ is $17.99 \mathrm{dBV} / \mathrm{m}$. 
International Journal on AdHoc Networking Systems (IJANS) Vol. 11, No. 3, July 2021

Farfield E-Field $(\mathrm{r}=1 \mathrm{~m})$ Abs (Phi=90)

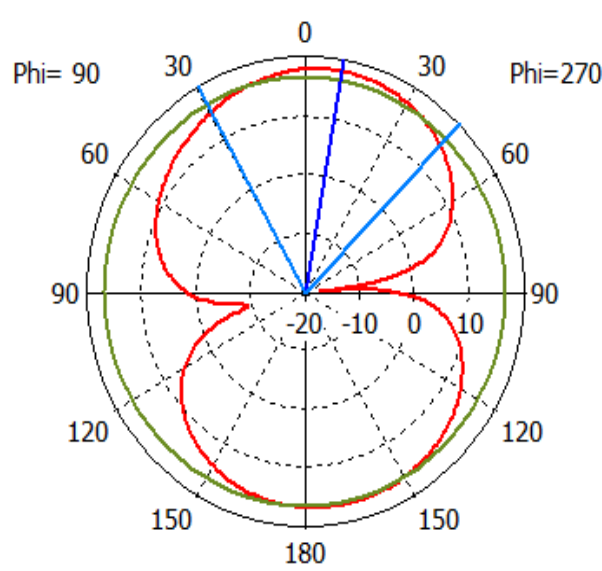

Theta / Degree vs. dBV/m

\section{Frequency $=5.5$}

Main lobe magnitude $=18 \mathrm{dBV} / \mathrm{m}$

Main lobe direction $=10.0 \mathrm{deg}$.

Angular width $(3 \mathrm{~dB})=74.0 \mathrm{deg}$.

Side lobe level $=-1.4 \mathrm{~dB}$

Figure 7. Polar plot of Far-field E-field pattern at $5.5 \mathrm{GHz}$

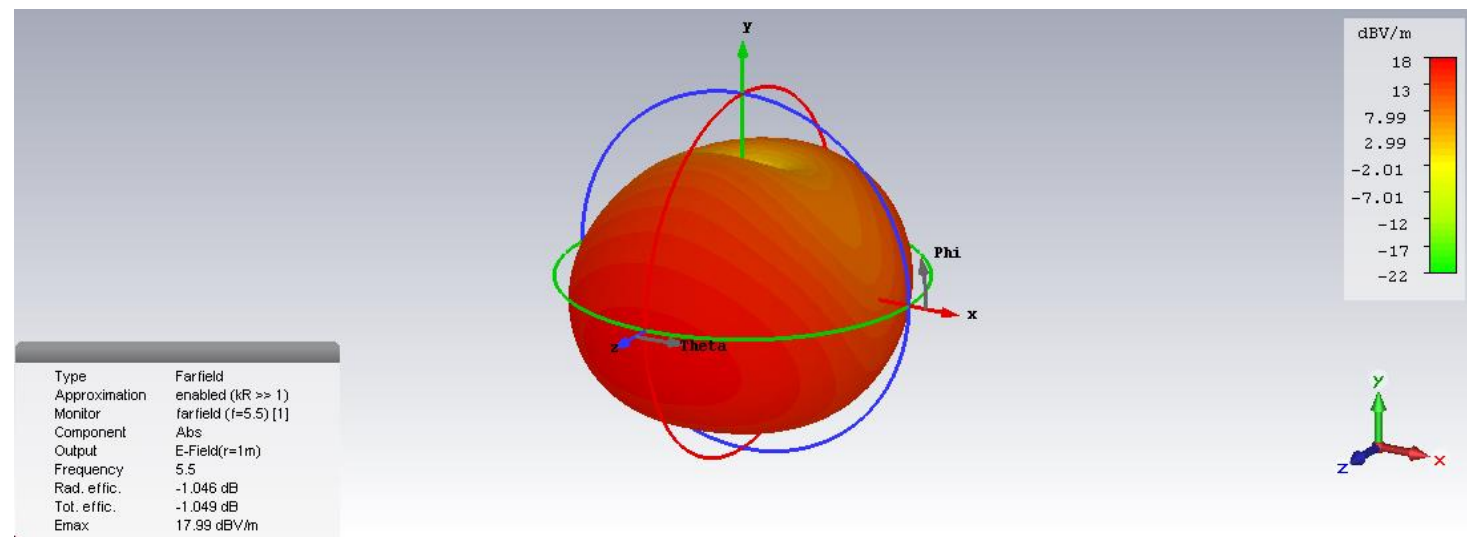

Figure 8. 3D plot of Far-field E-field pattern at $5.5 \mathrm{GHz}$

\subsubsection{H-field pattern}

Figure 9 shows the polar plot of Far-field H-field pattern of the proposed antenna at $5.5 \mathrm{GHz}$. It is seen that the main lobe magnitude is $-33.5 \mathrm{dBA} / \mathrm{m}$ and direction of main lobe is 10 degree. The 3D plot of the Far-field $\mathrm{H}$-field pattern of the designed antenna is shown in Fig. 10 which shows the maximum radiation intensity $\mathrm{H}_{\max }$ is $-33.53 \mathrm{dBV} / \mathrm{m}$. 
International Journal on AdHoc Networking Systems (IJANS) Vol. 11, No. 3, July 2021

Farfield H-Field $(\mathrm{r}=1 \mathrm{~m})$ Abs (Phi=90)

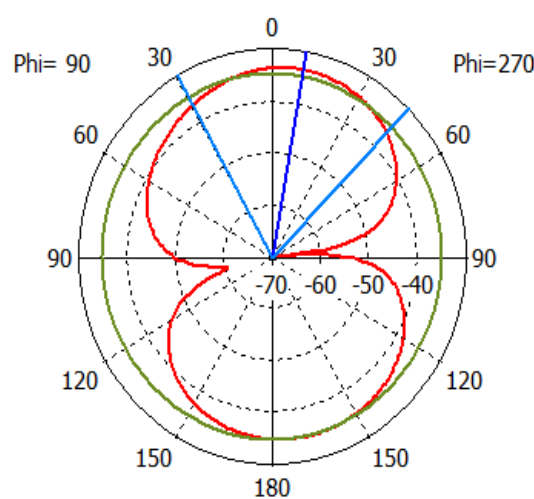

Theta / Degree vs, dBA/m
Frequency $=5.5$

Main lobe magnitude $=-33.5 \mathrm{dBA} / \mathrm{m}$

Main lobe direction $=10.0 \mathrm{deg}$.

Angular width $(3 \mathrm{~dB})=74.0 \mathrm{deg}$

Side lobe level $=-1.4 \mathrm{~dB}$

Figure 9. Polar plot of Far-field H-field pattern at $5.5 \mathrm{GHz}$

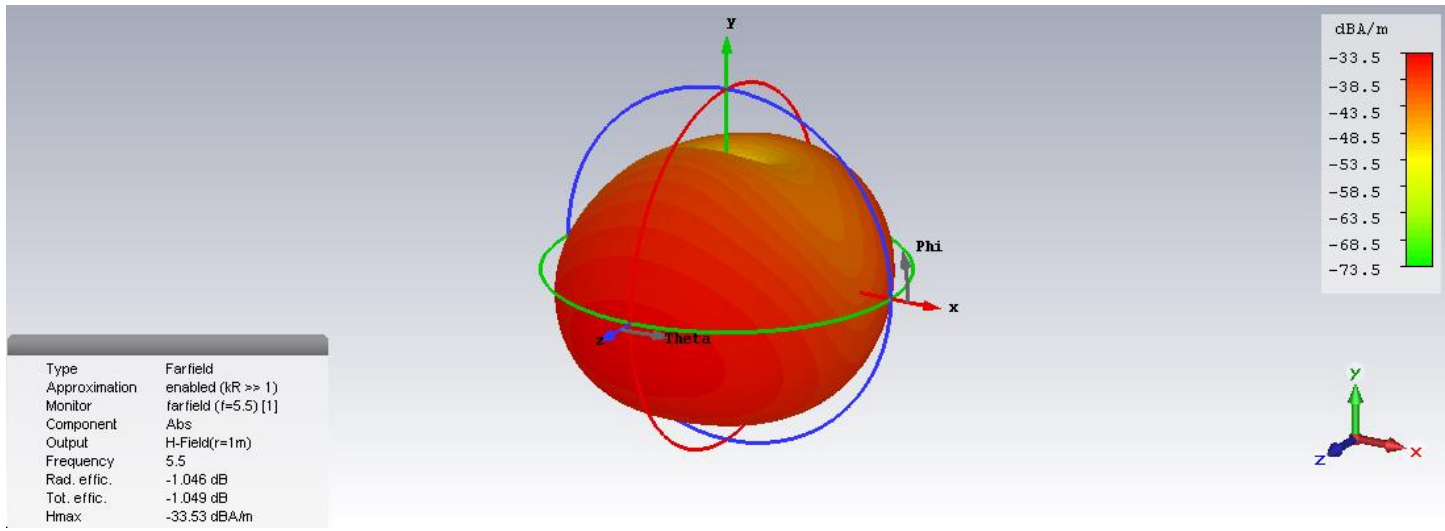

Figure 10. 3D plot of Far-field H-field pattern at $5.5 \mathrm{GHz}$

A summary of the above simulation results of the proposed compact designed circular microstrip patch antenna is presented in Table 2.

Table 2. Summary of simulation results of the proposed antenna

\begin{tabular}{|c|c|}
\hline Parameter & Value \\
\hline Resonance frequency & $5.5 \mathrm{GHz}$ \\
\hline Return loss & -31.5765 \\
\hline Bandwidth & $0.7019 \mathrm{GHz}$ (from $5.129 \mathrm{GHz}$ to $5.8309 \mathrm{GHz}$ ). \\
\hline VSWR & about $79 \%$ \\
\hline Total Efficiency & $3.229 \mathrm{~dB}$ \\
\hline Gain & $3.226 \mathrm{~dB}$ \\
\hline Realized Gain & $4.275 \mathrm{dBi}$ \\
\hline Directivity & \\
\hline
\end{tabular}




\section{Conclusion}

In this paper, we have proposed a compact circular microstrip patch antenna for WLAN applications which covers the band 5.15 to $5.825 \mathrm{GHz}$. To reduce the size of conventional antenna and to enhance the overall performance of the proposed antenna, a circular slot of radius $4.5 \mathrm{~mm}$ is loaded on circular patch and a square slot of dimensions $19 \times 19 \mathrm{~mm}$ is etched on the ground plane. The antenna is designed using CST Microsoft Studio Simulation Software. Various performance parameters like return loss, bandwidth, VSWR, gain, directivity, total efficiency and radiation pattern are studied. The proposed antenna resonates at the frequency of $5.5 \mathrm{GHz}$ with a wider bandwidth of $702 \mathrm{MHz}$ (from $5.129 \mathrm{GHz}$ to $5.8309 \mathrm{GHz}$ ) as expected. The antenna provides low return loss of $-31.58 \mathrm{~dB}$, good gain of $3.23 \mathrm{~dB}$ and directivity of $4.28 \mathrm{dBi}$ and high total efficiency of around $79 \%$ at $5.5 \mathrm{GHz}$. These parametric results indicate that the proposed compact designed circular microstrip patch antenna attains good performance and is suitable for WLAN applications. An optimization between size reduction and performance enhancement is maintained in this work.

In future work, we will focus on fabrication and testing of the proposed antenna and performance comparison of the simulated and fabricated antenna. The performance of this antenna can be further improved by cutting modified slots on the patch and ground plane, using different substrate materials. By integrating this proposed single elemental design antenna into an array on a single substrate, enhanced gain, directivity and efficiency can be obtained compared to its singular counterpart.

\section{REFERENCES}

[1] Y.T.Lo and S.W.Lee "Antenna Handbook Theory", Van Nostrand Reinhold Company, New York,1998.

[2] Antenna Theory, C.Balanis, Wiley, 2nd edition (1997), Chapter 14. ISBN 0- 471-59268-4.

[3] Herscovici, N., "New Considerations in the Design of Microstrip Antennas", IEEE Transactions on Antennas and Propagation, Volume 6, pp. 807-812, Jun. 1998.

[4] B.S. Sandeep, and, S.S. Kashyap "Design and Simulation of Microstrip Patch Array Antenna for Wireless Communication at 2.4GHz," International Journal of Scientific \& Engineering Research, Volume 3, No. 11, November, 2012.

[5] C. A. Balanis, Antenna theory: analysis and design. John Wiley \& Sons, 2005, Vol. 1.

[6] M. T. I.-u. Huque, M. Chowdhury, M. K. Hosain, and M. S. Alam, "Performance analysis of corporate feed rectangular patch element and circular patch element $4 \times 2$ microstrip array antennas," International Journal of Advanced Computer Science and Applications, vol. 2, no. 7,2011.

[7] R. Garg, Microstrip antenna design handbook. Artech House, 2001.

[8] M.Ranjan, "An Overview of Microstrip Antenna", HCTL Open International Journal of Technology Innovations and Research, Vol. 21, No. 2, August, 2016.

[9] A. Patil, , and B. Suryakanth, "A Survey and Review on Gain Enhancement Methods of Microstrip," International Journal on Emerging Technologies (Special Issue on NCRIET-2015) Volume 6, No. 2, pp. 98-104, 2015.

[10] A.A. Abdelaziz, "Bandwidth Enhancement of Microstrip Antenna," Progress in Electromagnetics Research, Volume 63, pp. 311-317, 2006.

[14] A.K. Arya, K.Machavaram, and A. Patnaik, "On the Size Reduction of Microstrip Antenna with DGS," $35^{\text {th }}$ InternationalConference on Infrared, Millimeter, and Terahertz Waves,September, 2010.

[15] S.S.Gaikwad, M. Singh, A. Ajey and S.S. Karthikayen, "Size Miniaturized Fractal Antenna for 2.5GHz Application," IEEE Students' Conference on Electrical Electronics and Computer Science, pp. 1-4, 2012.

[16] L.K. Fong, and R. Chair, "On the Use of Shorting Pins in the Design of Microstrip Patch Antennas," HKIE Transactions, Volume 11, No. 4, 2004. 
International Journal on AdHoc Networking Systems (IJANS) Vol. 11, No. 3, July 2021

[17] A. Trippe, , and S. Bhattacharya, "Compact Microstrip Antennas on a High Relative Dielectric Constant Substrate at $60 \mathrm{GHz}$," IEEE International Symposium on Antennas and Propagation, pp. 519-520, 2011

[18] H.W. Sang, Y.S. Lee, and J.G. Yook, "Wideband Microstrip Patch Antenna with U-Shaped Parasitic Elements," IEEE Transactions on Antennas and Propagation, Volume 55, pp. 1196-1199, 2007.

[19] Y. Hwang, Y.P.Zhang,, and T.K. Lo, "Probe-FedMicrostrip Antennas Loaded with Very HighPermittivity Ceramics: Research Articles," International Journal of RF and Microwave ComputerAided Engineering, Volume 16, No. 5, pp. 454-462 John Wiley and Sons Ltd. Chichester, UK, September, 2006.

[20] Ayyappan, Manoj. B, JagadishChandran, "Design and Analysis of Circular Microstrip Antenna at 5.8 GHz with Fr-4 substrate", International Journal of Advanced Research in Electrical, Electronics and Instrumentations Engineering, vol. 5, Special Issue 4, pp. 41-45, March 2016.

[21] Ritika Saini and Davinder Parkash, "Design and Simulation of CPW fed Slotted Circular Microstrip Antenna with DGS for Wireless Applications", International Journal of Applied Sciences and Engineering Research, Vol.3, Issue 1, pp. 82-90, 2014.

[22] Aishwarya R. Kulkarni, Snehal D. Barhate, PrachiBharude, R. V. Patil 4, ahesh N. Patil, "A Review on Circular Microstrip Patch Antenna," International Journal of Innovations in Engineering and Science, Vol 4, No.10, pp. 38-41, 2019.

[23] Nidhi M. Thaker, Vivek Ramamoorthy, "A Review on Circular Microstrip Patch Antenna with Slots for C Band Applications," International Journal of Scientific \& Engineering Research, Volume 5, Issue 12, pp. 1039-1043, December 2014.

[24] L. Nageswara Rao, B. Ramesh, V. Santhosh Kumar, “Design of Dual Band Circular Microstrip Patch Antenna with Slot for WLAN Applications," International Journal of Engineering \& Technology, 7 (2.7) pp. 451-455 (2018).

[25] Mrityunjoy Kumar Ray, " Design of a High Gain Circular Patch Antenna for GSM1800 Band," International Journal of Scientific and Research Publications, Volume 7, Issue 5, pp. 252-255, May 2017.

[26] Sonu Pandey and Karuna Markam, "Design and Analysis of Circular Shape Microstrip Patch Antenna for C-band Applications," International Journal of Advanced Research in Computer Science \& Technology, Vol. 4, Issue 2 , pp. 169-171, Apr. - Jun. 2016

[27] Neha Gupta, "Effects of Slots on Microsrip Patch Antenna", International Research Journal of Engineering and Technology, Vol. 4, Issue 2, pp. 1132-1135, February 2017.

[28] Manoj Singh, Ananjanbasu and S.K.Koul, "Circular Patch Antenna with Quarter wave Transformer Feed for Wireless Communications,” IEEE INDICON, pp.1-5, New Delhi, India, 15-17 Sep., 2006. 